\title{
The impact of continuous renal replacement therapy on renal outcomes in dialysis-requiring acute kidney injury may be related to the baseline kidney function
}

Marisa Aparecida de Souza Oliveira ${ }^{1,2}$, Thais Oliveira Claizoni dos Santos², Julio Cesar Martins Monte', Marcelo Costa Batista ${ }^{1,2}$, Virgilio Gonçalves Pereira $\mathrm{Jr}^{1}$, Bento Fortunato Cardoso dos Santos ${ }^{1}$,

Oscar Fernando Pavão Santos ${ }^{1,2}$ and Marcelino de Souza Durão Jr $r^{1,2^{*}}$

\begin{abstract}
Background: Many controversies exist regarding the management of dialysis-requiring acute kidney injury (D-AKI). No clear evidence has shown that the choice of dialysis modality can change the survival rate or kidney function recovery of critically ill patients with D-AKI.

Methods: We conducted a retrospective study investigating patients ( $\geq 16$ years old) admitted to an intensive care unit with D-AKI from 1999 to 2012. We analyzed D-AKI incidence, and outcomes, as well as the most commonly used dialysis modality over time. Outcomes were based on hospital mortality, renal function recovery (estimated glomerular filtration rate-eGFR), and the need for dialysis treatment at hospital discharge.
\end{abstract}

Results: In 1,493 patients with D-AKI, sepsis was the main cause of kidney injury (56.2\%). The comparison between the three study periods, (1999-2003, 2004-2008, and 2009-2012) showed an increased in incidence of D-AKI (from 2.56 to $5.17 \% ; p=0.001$ ), in the APACHE II score (from 20 to 26; $p<0.001$ ), and in the use of continuous renal replacement therapy (CRRT) as initial dialysis modality choice (from 64.2 to $72.2 \% ; p<0.001$ ). The mortality rate (53.9\%) and dialysis dependence at hospital discharge (12.3\%) remained unchanged over time. Individuals who recovered renal function (33.8\%) showed that those who had initially undergone CRRT had a higher eGFR than those in the intermittent hemodialysis group $(54.0 \times 46.0 \mathrm{ml} / \mathrm{min} / 1.73 \mathrm{~m} 2$, respectively; $p=0.014)$. In multivariate analysis, type of patient, sepsis-associated AKI and APACHE II score were associated to death. For each additional unit of the APACHE II score, the odds of death increased by $52 \%$. The odds ratio of death for medical patients with sepsis-associated AKI was estimated to be $2.93(1.81-4.75 ; p<0.001)$.

Conclusion: Our study showed that the incidence of D-AKI increased with illness severity, and the use of CRRT also increased over time. The improvement in renal outcomes observed in the CRRT group may be related to the better baseline kidney function, especially in the dialysis dependence patients at hospital discharge.

Keywords: Acute kidney injury, Dialysis, CRRT

\footnotetext{
* Correspondence: marcelino@einstein.br

${ }^{1}$ Nephrology Division of Hospital Israelita Albert Einstein, Avenida Albert

Einstein, 627, Morumbi, São Paulo 05652-900, Brazil

${ }^{2}$ Nephrology Division of Universidade Federal de São Paulo, Rua Botucatu,

740, Vila Clementino, São Paulo 04023-062, Brazil
} 


\section{Background}

Acute Kidney Injury (AKI), especially dialysis-requiring AKI (D-AKI), is associated with a poor prognosis. AKI increases the risk of developing chronic kidney disease (CKD) and death. Typically, AKI occurs while patients are hospitalized, mainly in intensive care units (ICU). These individuals usually have other comorbidities, and sepsis is a triggering factor [1-4].

Dialysis is the only specific therapy for treating AKI. The choice of dialysis modality is driven by a series of factors mainly related to the acute illness of patients, experience of nephrologists, and availability of technology and human resources. Depending on such factors, all modalities may be successfully applied to treat D-AKI $[5,6]$. However, an epidemiological study has shown that the most widely used modality to treat patients with DAKI in ICUs is continuous renal replacement therapy (CRRT) [7]. Many controversies exist regarding the management of AKI. For instance, no clear evidence has shown that the choice of dialysis modality can change the survival rate or kidney function recovery of D-AKI patients.

Therefore, we performed an epidemiological study to investigate D-AKI incidence, associated comorbidities, and outcomes for such patients, as well as the most commonly used dialysis modality in the ICU of a tertiary private hospital.

\section{Methods}

\section{Type of study and length of time}

A retrospective cohort study was performed in the ICU of Hospital Israelita Albert Einstein, São Paulo, Brazil, from January 1, 1999 to December 31, 2012.

The project was approved by institutional review board at Hospital Israelita Albert Einstein, under number 1715-13. Owing to the nature of the study, a waiver of consent agreement was requested. Data were kept strictly confidential.

\section{Inclusion criteria}

Patients treated with acute dialysis ( $\geq 16$ years old).

\section{Exclusion criteria}

Patients with CKD under a regular dialysis program and kidney transplant recipients.

\section{Variables}

Demographic, medical and laboratory (plasma creatinine and urea levels) data were collected from the hospital electronic medical records system, including the following information: age, gender, and main comorbidities such as liver disease, heart failure (HF), coronary artery disease (CAD), chronic obstructive pulmonary disease (COPD), acquired immunodeficiency syndrome (AIDS), malignant solid tumor, hematologic malignancies, solid organ transplant, and bone marrow transplant.

We analyzed the APACHE II system score [8], type of patient (medical or surgical patient), reasons for admission to the ICU, and etiology of AKI (including sepsis, ischemia due to low cardiac output, nephrotoxicity due to drugs, rhabdomyolysis, hepatorenal syndrome, and glomerulonephritis). The main sites of infection were identified in patients diagnosed with sepsis. We determined the length of stay in the hospital and ICU.

\section{Baseline renal function}

Baseline renal function was evaluated on the basis of plasma creatinine levels by considering the lowest level within the 3-month period prior to hospitalization, when available. If such data were unavailable, we recorded the lowest plasma creatinine value during hospitalization in the period without dialysis. The simplified formula of the MDRD [9] study was used to calculate the corresponding estimated glomerular filtration rate (eGFR).

\section{Time and dialysis modality}

No specific protocol was used to initiate the dialysis treatment or choose a certain dialysis method. Such factors were at the discretion of the nephrology team, and these factors were consistent throughout the period. Neither peritoneal dialysis nor hybrid procedures were commonly applied.

In our center, regarding the choice of initial renal replacement therapy modality, generally, unstable patients are managed with continuous therapies. These situations include: hypotensive subjects, shock, patients with multiple organ dysfunctions, use of mechanical ventilation, vasopressors, and inotropes. Patients with severe burns, multiple trauma, liver failure, brain injury, and pancreatitis are guided to CRRT as well. Less ill patients are treated with IHD.

The optimal time to start RRT in AKI remains uncertain. In addition to the usual indications such as uremia, hyperkalemia, hypervolemia, metabolic acidosis refractory to conservative measures, we usually initiate RRT in AKI in the following situations: persistently positive water balance, oliguria, severe sodium disorders, and hypercatabolism.

The first choice for vascular access placement was the right internal jugular vein. Alternatively, we used the femoral access (both sides) and the left internal jugular. Initially, we used temporary non-tunneled catheters with triple lumen. After 3 weeks of RRT and when there is no evidence of renal function improvement, we performed placement of a long-term hemodialysis catheter in internal jugular vein.

\section{Outcomes}

Outcomes were based on hospital mortality, renal function recovery, and the need for dialysis treatment at 
hospital discharge. We evaluated the eGFR at hospital discharge of patients with recovering renal function.

\section{Follow-up period}

Until hospital discharge.

\section{Statistical analysis}

Absolute frequencies and percentages were used to describe qualitative variables. In the case of asymmetry, means and standard deviations or medians and interquartile intervals $\left(25-75^{\text {th }}\right)$ were used to describe quantitative variables. Histograms and Shapiro-Wilk normality tests were used to analyze the distribution of numerical variables.

Logistic regression models for simple and multiple regressions were used to analyze the factors associated with death among patients with AKI. After selecting the variables, interactions were investigated. Only the final multiple model obtained is shown.

The SPSS program (Version 17.0. Chicago: SPSS Inc.) was used to perform statistical analyses, and the significance level cutoff was $95 \%$.

\section{Results}

Within a 14-year period, we identified 1,493 patients with D-AKI (Table 1). Most were male (65.0\%) and white $(92.5 \%)$, and their average age was $63 \pm 18$ years. The main comorbidities were diabetes (36.2\%), systemic arterial hypertension (36.0\%), and cardiovascular disease (36.0\%). A total of 526 individuals had been submitted to solid organ transplants (35.2\%), mainly liver transplants. We found 839 cases of AKI related to sepsis (56.2\%). Others causes of AKI were low cardiac output $(N=270,18.1 \%)$, drug-induced nephrotoxicity $(N=186$, $12.5 \%)$, hepatorenal syndrome $(N=81,5.4 \%)$, rhabdomyolysis $(N=74,5.0 \%)$, glomerulonephritis $(N=23,1.5 \%)$, and unknown $(N=20,1.3 \%)$. The most common types of infection were pulmonary (43.7\%) and abdominal (37.3\%).

The APACHE II score was 23 (18-30), and the basal eGFR was $84(49-106) \mathrm{ml} / \mathrm{min} / 1.73 \mathrm{~m}^{2}$.

The most commonly used dialysis modality was continuous dialysis (66.4\%), consisting exclusively of venovenous hemodiafiltration (CVVHDF); the second most common was intermittent hemodialysis (IHD) (33.6\%). Of all patients who initially performed IHD, 136 individuals $(27 \%)$ had to undergo CVVHDF due to medical condition worsening during the course of the disease. Of those who first performed CVVDHF, 526 subjects (53\%) were de-escalated for IHD due to illness improvement.

The overall death rate was $53.9 \%$. The ICU and hospital lengths of stay were 12 (6-24) and 30 (15-52) days, respectively. In addition, $12.3 \%$ patients required dialysis at hospital discharge. The remaining patients (33.8\%) recovered at least partial renal function.
Table 1 Description of the main clinical and demographic data

\begin{tabular}{|c|c|c|}
\hline Variables & $(N=1,493)$ & $\%$ \\
\hline Gender (male) N (\%) & 970 & $65.0 \%$ \\
\hline Age (years) mean (SD) & 63 & 18 \\
\hline \multicolumn{3}{|l|}{ Race N (\%) } \\
\hline White & 1381 & $92.5 \%$ \\
\hline \multicolumn{3}{|l|}{ Comorbidities N (\%) } \\
\hline DM & 541 & $36.2 \%$ \\
\hline $\mathrm{AH}$ & 537 & $36.0 \%$ \\
\hline $\mathrm{HD}$ & 528 & $35.4 \%$ \\
\hline COPD & 153 & $10.2 \%$ \\
\hline Malignant solid tumor & 200 & $13.4 \%$ \\
\hline Hematologic malignances and BMT & 107 & $7.2 \%$ \\
\hline Cirrhosis/other liver diseases & 100 & $6.7 \%$ \\
\hline Solid organ transplant & 526 & $35.2 \%$ \\
\hline Liver & 509 & $34.1 \%$ \\
\hline Heart & 14 & $0.9 \%$ \\
\hline Lung & 2 & $0.1 \%$ \\
\hline Multivisceral & 1 & $0.1 \%$ \\
\hline \multicolumn{3}{|l|}{ Type of patient $N(\%)$} \\
\hline Medical & 1094 & $73.3 \%$ \\
\hline Surgical & 399 & $26.7 \%$ \\
\hline \multicolumn{3}{|l|}{ Reason for admission to ICU N (\%) } \\
\hline Infection & 577 & $38.6 \%$ \\
\hline Cardiovascular disease & 399 & $26.7 \%$ \\
\hline Pancreatitis & 58 & $3.9 \%$ \\
\hline Bleeding & 48 & $3.2 \%$ \\
\hline Intoxication & 12 & $0.8 \%$ \\
\hline Surgical urgency & 339 & $22.7 \%$ \\
\hline Elective surgery & 19 & $1.3 \%$ \\
\hline Trauma & 33 & $2.2 \%$ \\
\hline Major burn & 8 & $0.5 \%$ \\
\hline \multicolumn{3}{|l|}{ AKI etiology $N(\%)$} \\
\hline Sepsis & 839 & $56.2 \%$ \\
\hline Low cardiac output & 270 & $18.1 \%$ \\
\hline
\end{tabular}

RRT modality $N(\%)$

$\mid H D$

$33.6 \%$

CWHDF

$66.4 \%$

Death $N(\%)$

$53.9 \%$

Baseline creatinine $(\mathrm{mg} / \mathrm{dl})$ median (IQR) $\quad 0.9 \quad(0.7-1.5)$

eGFR-ml/min/1.73 $\mathrm{m}^{2}$ median (IQR)

APACHE II median (IQR) 23

ICU length of stay (days) - median (IQR) 12

Hospital length of stay (days) - median (IQR) $30 \quad$ (15-52)

$D M$ diabetes mellitus, $A H$ arterial hypertension, $H D$ heart diseases, COPD chronic obstructive pulmonary disease, BMT bone marrow transplantation, $I C U$ intensive care unit, $R R T$ renal replacement therapy, IHD intermittent hemodialysis, CVVHDF continuous venovenoushemodiafiltration, eGFR estimated glomerular filtration rate, APACHE Acute Physiology And Chronic Health Evaluation, $S D$ standard deviation, IQR interquartile range 


\section{Comparison of the APACHE II scores, on the basis of dialysis modality}

The APACHE score was assessed according to initial dialysis method. The APACHE median was 19 (16-25) for patients who had undergone IHD and 26 (20-30) for those who had undergone CVVHDF $(p<0.001)$.

\section{Comparison of the death rates, on the basis of dialysis modality}

The death rate was $64.2 \%$ for patients who had undergone CVVHDF and $33.5 \%$ for those who had undergone IHD $(p<0.001)$. However, as reported above, on the basis of APACHE II scores, the severity of illness was greater for individuals who had initially undergone CVVHDF.

Comparison of dialysis dependence at hospital discharge, on the basis of dialysis modality

Patients who had initially undergone IHD showed a greater dependence on dialysis support at hospital discharge than those who had initially undergone CVVHDF (33.6 vs. $20.3 \%, p<0.001$ ). However, significant differences were observed relative to the baseline eGFR among individuals in the two groups. Patients who had undergone IHD had a lower baseline eGFR than those who had undergone CVVHDF (43.3 and $85.1 \mathrm{ml} / \mathrm{min} / 1.73 \mathrm{~m}^{2}$, respectively, $p<0.001$ ) (Table 2 ).

\section{Comparison of the eGFR at hospital discharge (individuals who recovered renal function), on the basis of dialysis modality}

A comparison of the eGFR at discharge and the initial dialysis modality chosen was performed. The median
eGFR was $46.0(35-68) \mathrm{ml} / \mathrm{min} / 1.73 \mathrm{~m}^{2}$ for patients who underwent IHD and $54.0(39-72) \mathrm{ml} / \mathrm{min} / 1.73 \mathrm{~m}^{2}$ for those who underwent CVVHDF $(p=0.014)$.

In the group of survivors who recovered renal function, the baseline median eGFR was $79.3(42-107) \mathrm{ml} / \mathrm{min} /$ $1.73 \mathrm{~m}^{2}$ for patients who underwent IHD and 87.8 (52-110) $\mathrm{ml} / \mathrm{min} / 1.73 \mathrm{~m}^{2}$ for those who underwent CVVHDF $(p=0.101)$ (Table 2).

Comparison of the three periods: 1999-2003, 2004-2008 and 2009-2012

To evaluate the changes in multiple variables over time, the total study time was divided into three periods: 1999 to 2003 (5 years), 2004 to 2008 (5 years) and 2009 to 2012 ( 4 years). The numbers of patients hospitalized in the ICU during these three periods were 10,565, 12,312 and 12,251, respectively.

These three periods are compared in Table 3. Significant changes were observed in the percentage of patients with liver disease who were submitted to liver transplantation, which increased from 19.2\% during the first period to $41.2 \%$ during the third period $(p<0.001)$.

A significant change was also found regarding the choice of initial dialysis method during the time periods. CVVHDF selection increased from $64.2 \%$ during the first period to $72.2 \%$ during the third period $(p<0.001)$.

A significant change in the APACHE II score was also observed. The median score was 20 during the first period, 25 during the second period and 26 during the third period $(p<0.001)$. No significant changes were found in the percentage of sepsis-induced AKI cases, use of vasopressors, use of mechanical ventilation or patient outcomes.

Table 2 Renal function and outcomes between the IHD and CWHDF groups

\begin{tabular}{|c|c|c|c|}
\hline & $\operatorname{IHD}(501)$ & CWHDF (992) & $P$ value \\
\hline APACHE score & $19(16-25)$ & $26(20-30)$ & $<0.001$ \\
\hline Creatinine baseline $(\mathrm{mg} / \mathrm{dL})^{\mathrm{a}}$ & $1.05(0.8-1.9)$ & $0.9(0.7-1.2)$ & $<0.001$ \\
\hline eGFR baseline $\left(\mathrm{mL} / \mathrm{min} / 1.73 \mathrm{~m}^{2}\right)^{\mathrm{a}}$ & $69.5(34.1-100.9)$ & $87.6(51.1-109.2)$ & $<0.001$ \\
\hline Creatinine in the beginning of RRT (mg/dl) & $3.7(3.1-4.5)$ & $3.6(3.1-4.1)$ & $<0.001$ \\
\hline Urea in the beginning of RRT (mg/dL) & $139(106-176)$ & $140(107-174)$ & 0.596 \\
\hline Death & $168(33.5 \%)$ & $637(64.2 \%)$ & $<0.001$ \\
\hline Patients who remained dependent on dialysis at hospital discharge ${ }^{b}$ & $112(33.6 \%)$ & $72(20.3 \%)$ & $<0.001$ \\
\hline eGFR baseline $\left(\mathrm{mL} / \mathrm{min} / 1.73 \mathrm{~m}^{2}\right)$ in dialysis dependence patients & $43.3(26.9-86.0)$ & $85.1(49.4-99.5)$ & $<0.001$ \\
\hline Patients who recovered renal function ${ }^{\text {b }}$ & $221(66.4 \%)$ & $283(79.7 \%)$ & $<0.001$ \\
\hline eGFR baseline $\left(\mathrm{mL} / \mathrm{min} / 1.73 \mathrm{~m}^{2}\right)$ in renal recovery patients & $79.3(42.3-107.2)$ & $87.8(51,7-110.5)$ & 0.101 \\
\hline Creatinine discharge $(\mathrm{mg} / \mathrm{dL})$ in renal recovery patients & $1.6(1.1-1.9)$ & $1.3(1.0-1.8)$ & 0.014 \\
\hline eGFR discharge $\left(\mathrm{mL} / \mathrm{min} / 1,73 \mathrm{~m}^{2}\right)$ in renal recovery patients & $46.0(34.6-68.8)$ & $54.0(38.7-72.2)$ & 0.011 \\
\hline
\end{tabular}

Values expressed as median (interquartile range) or number (percentage)

IHD intermittent haemodialysis, CVVHDF continuous venovenous hemodiafiltration, APACHE Acute Physiology And Chronic Health Evaluation, eGFR estimated glomerular filtration rate, $R R T$ renal replacement therapy

${ }^{a} 488$ patients in de IHD group and 960 patients in CVVHDF group

$\mathrm{b}_{\%}$ values calculated from the number of survivors 
Table 3 Comparison of the three periods (time-stratified data)

\begin{tabular}{|c|c|c|c|c|c|c|c|}
\hline & \multicolumn{6}{|c|}{ Evaluated periods } & \multirow[t]{2}{*}{$P$} \\
\hline & \multicolumn{2}{|c|}{ 1999-2003 } & \multicolumn{2}{|c|}{$2004-2008$} & \multicolumn{2}{|c|}{$2009-2012$} & \\
\hline AKI N (incidence-\%) & \multicolumn{2}{|c|}{$271(2.56 \%)$} & \multicolumn{2}{|c|}{$588(4.77 \%)$} & \multicolumn{2}{|c|}{$634(5.17 \%)$} & 0.001 \\
\hline \multicolumn{8}{|l|}{ Liver disease and liver transplant N (\%) } \\
\hline Cirrhosis/other liver diseases & 21 & $7.70 \%$ & 27 & $4.60 \%$ & 52 & $8.20 \%$ & $<0.001$ \\
\hline Liver transplant & 52 & $19.20 \%$ & 197 & $33.50 \%$ & 261 & $41.20 \%$ & \\
\hline Heart disease $N(\%)$ & 94 & $34.70 \%$ & 228 & $38.80 \%$ & 206 & $32.50 \%$ & 0.069 \\
\hline Malignant solid tumor N (\%) & 42 & $15.50 \%$ & 78 & $13.30 \%$ & 80 & $12.60 \%$ & 0.504 \\
\hline Solid organ transplant $N(\%)$ & 52 & $19.20 \%$ & 200 & $34.00 \%$ & 274 & $43.20 \%$ & $<0.001$ \\
\hline Hematologic malignances and BMT N (\%) & 19 & $7.00 \%$ & 46 & $7.80 \%$ & 42 & $6.60 \%$ & 0.715 \\
\hline Sepsis-AKI N (\%) & 148 & $54.60 \%$ & 329 & $56.00 \%$ & 362 & $57.10 \%$ & 0.779 \\
\hline \multicolumn{8}{|l|}{ RRT modality $N(\%)$} \\
\hline Hemodialysis & 97 & $35.80 \%$ & 228 & $38.80 \%$ & 176 & $27.80 \%$ & $<0.001$ \\
\hline Continuous dialysis & 174 & $64.20 \%$ & 360 & $61.20 \%$ & 458 & $72.20 \%$ & \\
\hline \multicolumn{8}{|l|}{ Outcomes N (\%) } \\
\hline Death & 158 & $58.30 \%$ & 312 & $53.10 \%$ & 335 & $52.80 \%$ & 0.352 \\
\hline Dialysis dependence & 26 & $9.60 \%$ & 81 & $13.80 \%$ & 77 & $12.10 \%$ & \\
\hline Recovery of renal function & 87 & $32.10 \%$ & 195 & $33.20 \%$ & 222 & $35.00 \%$ & \\
\hline Vasopressors N (\%) & 257 & $94.80 \%$ & 558 & $94.90 \%$ & 593 & $93.50 \%$ & 0.541 \\
\hline Mechanical ventilation N (\%) & 231 & $85.20 \%$ & 502 & $85.40 \%$ & 544 & $85.80 \%$ & 0.966 \\
\hline APACHE II score median (IQR) & 20 & $(19-22)$ & 25 & $(18-29)$ & 26 & $(18-31)$ & $<0.001$ \\
\hline Age (years) mean (SD) & 64 & 18 & 65 & 18 & 61 & 18 & $<0.001$ \\
\hline
\end{tabular}

$A K I$ acute kidney injury, BMT bone marrow transplantation, RRT renal replacement therapy, APACHE Acute Physiology And Chronic Health Evaluation, SD standard deviation, $I Q R$, interquartile range

\section{Mortality risk factors}

By univariate analysis, heart disease $(1,38[1,12-1,71$; $p=0,003]$ ), hematologic malignancy and bone marrow transplantation $(2,21 \quad[1,44-3,40 ; p<0.001])$, cirrhosis and liver transplantation $(2,61[1,66-4,11 ; p<0.001])$, solid organ malignancy $(1,30[0,96-1,76 ; p=0.089])$, surgi$\mathrm{cal} /$ medical patients $(0,42[0,33-0,53 ; p<0.001])$, sepsisassociated AKI $(2,06[1,68-2,54 ; p<0.001])$, CRRT as first choice dialysis modality $(3,56[2,84-4,46 ; p<0.001])$, use of vasopressor $(14,58[6,68-31,81 ; p<0.001])$, use of mechanical ventilation $(7,57[5,20-11,01 ; p<0.001])$, APACHE II score $(1,54[1,48-1,60 ; p<0.001])$ and baseline eGFR $(1,00$ $[1,00-1,01 ; p=0.067])$ correlated with death.

In the multivariate analysis, variables that remained significant in the model were selected, including type of patient, sepsis-associated AKI and APACHE II score. We observed a significant interaction between the patient type and etiology of AKI; i.e., the effect of patient type on the risk of death depends on the etiology of AKI. From this finding, we constructed a variable according to the combination of the patient type and the etiology of AKI, with the following categories: medical patient with non-sepsis-associated AKI, medical patient with sepsis-associated AKI, surgical patient with non- sepsis-associated AKI and surgical patient with sepsisassociated AKI. The results of the final adjusted model are shown in Table 4.

For each additional unit of the APACHE II score, the odds of death increased by $52 \%$.

The odds ratio of death for medical patients with sepsis-associated AKI was estimated to be 2.93 [1.81-4.75; $p<0.001]$.

Table 4 Multivariate analysis of the factors associated with death

\begin{tabular}{llc}
\hline & Odds ratio $(95 \% \mathrm{Cl})$ & $p$ \\
\hline $\begin{array}{l}\text { Type of patient and cause of AKI } \\
\text { Medical patient with non-septic-AKI/ }\end{array}$ & $2.54(1.50-4.32)$ & 0.001 \\
$\begin{array}{l}\text { Surgical patient with non-septic-AKI } \\
\text { Medical patient with septic-AKI/ }\end{array}$ & $2.93(1.81-4.75)$ & $<0.001$ \\
$\begin{array}{l}\text { Surgical patient with non-septic-AKI } \\
\text { Surgical patient with septic-AKI/ }\end{array}$ & $2.50(1.27-4.92)$ & 0.008 \\
$\begin{array}{l}\text { Surgical patient with non-septic-AKI } \\
\text { APACHE II score }\end{array}$ & $1.52(1.46-1.58)$ & $<0.001$ \\
\hline $\begin{array}{l}\text { AKI acute kidney injury, Acute Physiology And Chronic Health Evaluation, } \mathrm{Cl} \\
\text { confidence interval }\end{array}$
\end{tabular}




\section{Discussion}

Our cohort showed an increase in D-AKI rates in the ICU over time. Observational studies have also indicated that the overall incidence of AKI has increased during recent decades $[10,11]$. The incidence of AKI requiring dialysis has also increased [12, 13]. Recent data have shown that most individuals develop AKI while being hospitalized in the ICU. In this scenario, the need for dialysis ranges from 5 to $10 \%[7,14]$. Similar rates were found in our sample.

Although we did not observe an increase in the use of vasopressors or mechanical ventilation at the beginning of the dialysis therapy, a temporal analysis showed an increase in the severity of illness, a larger number of patients submitted to solid organ transplants, mainly liver transplants, and an increase in patients with cirrhosis and other liver diseases. The number of solid organ transplants has been increasing worldwide [15]. Patients often experience medical conditions that worsen during the perioperative period (e.g., hypotension, shock, and bleeding). Because of the use of immunosuppressive medications, they are subject to infections, complications from drug interactions, and cardiovascular disorders, all of which ultimately lead to ICU admissions.

Liver transplant patients are susceptible to AKI development mainly because of the effects of liver disease on renal function, but also because of the reasons mentioned above [16]. Several studies have shown that some liver transplant recipients have hepatorenal syndrome, and others use nephrotoxic drugs as antibiotics and contrast agents during the pre-transplant period. Hypotension and the use of vasopressors, graft dysfunction, the need for surgical intervention, transfusion of blood products and bacterial infections are some of the most common factors associated with the development of AKI during the liver posttransplant period $[17,18]$.

This study showed that sepsis is a leading cause of AKI over time (greater than $50 \%$ of the cases). Despite the seemingly decreasing rate of mortality from sepsis, some studies have shown that the rates of sepsis or septic shock have been increasing at an annual rate of 8 to $13 \%[19,20]$. In this context, data have also indicated that sepsis is the main factor associated with the development of AKI, especially in the ICU [21, 22]. A clear association has also been found between the severity of illness and the stage of AKI [23-25]. In our sample, we noted an increased APACHE II score over time concomitant with the increased incidence of D-AKI.

The initial dialysis modality most often used was CVVHDF, which was also observed to increase over the three periods studied. Epidemiological data have shown that continuous modalities are more widely used in the treatment of patients with AKI in the ICU. In some regions, CRRT is used exclusively [7]. Recent, larger trials have shown that sicker patients who are hemodynamically unstable tend to receive continuous or hybrid therapies $[22,26]$. The theoretical advantage of this type of procedure is that it allows for greater removal of fluids while maintaining hemodynamic stability. The constant removal of solutes thus avoids sudden changes in plasma osmolality, especially in individuals with intracranial hypertension. Continuous modalities provide better adjustment of metabolic acidosis and metabolic control for hypercatabolic individuals, and induce possible immunomodulatory effects [27-29].

Despite advances in the management of patients with AKI, most studies have shown persistently high mortality rates. Others have indicated a slight decrease in mortality [30]. In our study, regardless of the increase in the APACHE II score, the mortality rate remained unchanged over time. Individuals who had initially undergone CVVHDF had a higher mortality rate than those who had undergone IHD. However, patients in the CVVHDF group had a greater APACHE II score at ICU admission, which increases the difficulty of assessing the two groups. Most studies that have compared continuous therapies with IHD have shown no evident benefit with regard to survival rates [31]. Larger trials have evaluated the dialysis dose for patients with AKI in the ICU. In these studies, the most severe patients were directed to CRRT as the first choice of treatment, which appears to be a universal practice $[22,26]$. Recently, hybrid therapies have emerged as an alternative to treat such individuals and appear to have the same advantages as CRRT [32].

Another important aspect regarding outcomes is dialysis dependence at hospital discharge and in the longterm. Some observational studies have suggested that dialysis therapies may influence the recovery of renal function after an episode of AKI. Thus, continuous therapies seem to decrease the need for dialysis compared with conventional hemodialysis [33, 34]. In our cohort, we observed that the subjects who had initially undergone IHD had a higher rate of dialysis dependence at hospital discharge than those who underwent CVVHDF first. However, we noted that the individuals in the IHD group had a lower baseline eGFR than those in the CVVHDF group. Because the presence of CKD is one of the main risk factors for lasting kidney impairment after an AKI episode, it was impossible to compare these groups.

A simple analysis of individuals who survived and recovered renal function showed that those who had initially undergone CVVHDF had a higher GFR than those in the IHD group at time of hospital discharge. No significant difference was observed in the baseline eGFR between the two groups. Theoretically, continuous therapy may preserve kidney function, thereby maintaining the hemodynamic status and reducing hypotension episodes, especially during fluid withdrawal. However, 
eGFR at hospital discharge may overestimate renal function of these individuals in both groups (CVVHDF and IHD) because of loss of muscle mass that occurs during the course of a serious illness [35].

In the multivariate analysis, the APACHE II score and sepsis-associated AKI in medical patients were independent risk factors related to death. Bagshaw and cols. have shown that sepsis-induced AKI occurs more frequently in medical patients with higher severity illness scores on ICU admission. Such individuals have longer hospital stays and exhibit higher mortality rates than those of patients with AKI not associated with sepsis [36].

Our study has some limitations. This is an observational, single-center study, and the comparative analysis between groups was subject to bias. No specific protocol was used for the choice of the first dialysis modality. The decision was made by the nephrology team, although the team remained constant throughout the study period. Our center performs only CVVHDF and IHD. Other modalities, such as hybrid therapies and peritoneal dialysis, were not addressed. The timing of RRT initiation and dialysis dose were not evaluated. The follow-up period was restricted to the time of hospital discharge, and some AKI complications may arise in the medium- and long-term periods.

Often, unstable patients do not tolerate IHD and are guided to CRRT. There is also a transition between therapies during the evolution of the disease, which makes it difficult to perform randomized clinical studies comparing the dialysis modalities.

\section{Conclusions}

In conclusion, our study showed that the incidence of DAKI increased with illness severity, and the use of CRRT also increased. Sepsis was the main cause of AKI. The mortality rate and need for dialysis after an episode of AKI remained stable over time. The improvement in renal outcomes observed in the CRRT group may be related to the better baseline kidney function, especially in the dialysis dependence patients at hospital discharge. Medical patients, sepsis-associated AKI and higher APACHE II scores were the independent risk factors associated with death. Strategies to reduce or enable a specific treatment for sepsis-associated AKI should be established. Despite the difficulties, randomized clinical trials comparing continuous and intermittent therapies are needed to evaluate the recovery of renal function as a primary outcome.

\section{Additional file}

Additional file 1: Data generated. (XLS $520 \mathrm{~kb}$ )

\section{Abbreviations}

AIDS: Acquired immunodeficiency syndrome; AKl: Acute kidney injury;

CAD: Coronary artery disease; CKD: Chronic kidney disease; COPD: Chronic obstructive pulmonary disease; CRRT: Continuous renal replacement therapy; CWHDF: Continuous venovenous hemodiafiltration; D-AKI: Dialysis-requiring AKl; EGFR: Estimated glomerular filtration rate; HF: Heart failure; ICU: Intensive care unit; IHD: Intermittend hemodialysis

Acknowledgments

We thank Elivane da Silva Victor for statistical analysis.

\section{Funding}

This research received no specific grant from any funding agency.

Availability of data and materials

All data generated or analysed during this study are included in this manuscript and its Additional file 1.

\section{Authors' contributions}

MASO, TOCS and MSDJ participated in the study design, analysis and interpretation, and manuscript writing. JCMM, MCB, VGPJ, BFCS and OFPS participated in the data collection revised the manuscript critically and helped with correct interpretation of data. All authors read and approved the final manuscript.

\section{Competing interests}

The authors declare that they have no competing interests.

Consent for publication

Not applicable.

\section{Ethics approval and consent to participate}

The project was approved by institutional review board at Hospital Israelita Albert Einstein, under approval number 1715-13. Owing to the nature of the study, a waiver of consent agreement was requested. Data were kept strictly confidential.

\section{Publisher's Note}

Springer Nature remains neutral with regard to jurisdictional claims in published maps and institutional affiliations.

Received: 4 November 2016 Accepted: 20 April 2017

Published online: 03 May 2017

\section{References}

1. Liangos O, Wald R, O'Bell JW, Price L, Pereira BJ, Jaber BL. Epidemiology and outcomes of acute renal failure in hospitalized patients: a national survey. Clin J Am Soc Nephrol. 2006:1(1):43-51.

2. Chertow GM, Soroko SH, Paganini EP, Cho KC, Himmelfarb J, Ikizler T, et al. Mortality after acute renal failure: models for prognostic stratification and risk adjustment. Kidney Int. 2006;70(6):1120-6.

3. Susantitaphong P, Cruz DN, Cerda J, Abulfaraj M, Alqahtani F, Koulouridis I, et al. World incidence of AKl: A meta-analysis. Clin J Am Soc Nephrol. 2013; 8(9):1482-93.

4. Alobaidi R, Basu RK, Goldstein SL, Bagshaw SM. Sepsis-associated acute kidney injury. Semin Nephrol. 2015;35(1):2-11.

5. Palevsky PM. Renal replacement therapy in acute kidney injury. Adv Chronic Kidney Dis. 2013;20(1):76-84.

6. Ronco C, Ricci Z, De Backer D, Kellum J, Taccone FS, Joannidis M, et al. Renal replacement therapy in acute kidney injury: controversy and consensus. Crit Care. 2015:19(1):146.

7. Uchino S, Kellum JA, Bellomo R, Doig GS, Morimatsu H, Morgera S, et al. Acute renal failure in critically ill patients: a multinational, multicenter study. JAMA. 2005;294(7):813-8.

8. Knaus WA, Draper EA, Wagner DP, Zimmerman JE. APACHE II: a severity of disease classification system. Crit Care Med. 1985;13(10):818-29.

9. Levey AS, Bosch JP, Lewis JB, Greene T, Rogers N, Roth D. A more accurate method to estimate glomerular filtration rate from serum creatinine: a new prediction equation. Modification of Diet in Renal Disease Study Group. Ann Intern Med. 1999:130(6):461-70.

10. Xue JL, Daniels F, Star R, Kimmel PL, Eggers PW, Molitoris B, et al. Incidence and mortality of acute renal failure in Medicare beneficiaries, 1992 to 2001. J Am Soc Nephrol. 2006;17(4):1135-42. 
11. Hsu C-Y, McCulloch CE, Fan D, Ordoñez JD, Chertow GM, Go AS. Communitybased incidence of acute renal failure. Kidney Int. 2007;72(2):208-12.

12. Hsu RK, McCulloch CE, Dudley RA, Lo LJ, Hsu C. Temporal changes in incidence of dialysis-requiring AKI. J Am Soc Nephrol. 2013;24(1):37-42.

13. Metcalfe W, Simpson M, Khan IH, Prescott GJ, Simpson K, Smith WCS, et al. Acute renal failure requiring renal replacement therapy: incidence and outcome. QJM. 2002;95(9):579-83.

14. Nisula S, Kaukonen KM, Vaara ST, Korhonen AM, Poukkanen M, Karlsson S, et al. Incidence, risk factors and 90-day mortality of patients with acute kidney injury in Finnish intensive care units: The FINNAKI study. Intensive Care Med. 2013;39(3):420-8.

15. Organ Procurement and Transplantation Network (OPTN) and Scientific Registry of Transplant Recipients (SRTR). OPTN/SRTR 2010 Annual Data Report. Rockville, MD: Department of Health and Human Services, Health Resources and Services Administration. http://srtr.transplant.hrsa.gov/ annual_reports (2011). Acessed 2 Feb 2016.

16. Karvellas CJ, Durand F, Nadim MK. Acute kidney injury in Cirrhosis. Crit Care Clin. 2015;31(4):737-50

17. Hilmi IA, Damian D, Al-Khafaji A, Planinsic R, Boucek C, Sakai T, et al. Acute kidney injury following orthotopic liver transplantation: Incidence, risk factors, and effects on patient and graft outcomes. Br J Anaesth. 2015;114(6):919-26.

18. Utsumi M, Umeda Y, Sadamori H, Nagasaka T, Takaki A, Matsuda H, et al. Risk factors for acute renal injury in living donor liver transplantation: evaluation of the RIFLE criteria. Transpl Int. 2013;26(8):842-52.

19. Martin GS, Mannino DM, Eaton S, Moss M. The epidemiology of sepsis in the United States from 1979 through 2000. N Engl J Med. 2003;348(16):1546-54.

20. Gaieski DF, Edwards JM, Kallan MJ, Carr BG. Benchmarking the incidence and mortality of severe sepsis in the United States. Crit Care Med. 2013; 41(5):1167-74.

21. Durão MS, Monte JCM, Batista MC, Oliveira M, lizuka IJ, Santos BF, et al. The use of regional citrate anticoagulation for continuous venovenous hemodiafiltration in acute kidney injury. Crit Care Med. 2008:36(11):3024-9.

22. Bellomo R, Cass A, Cole L, Finfer S, Gallagher M, Lo S, et al. Intensity of continuous renal-replacement therapy in critically ill patients. RENAL Replacement Therapy Study Investigators. N Engl J Med. 2009;361(17):1627-38.

23. Rangel-Frausto MS, Pittet D, Costigan M, Hwang T, Davis CS, Wenzel RP. The natural history of the systemic inflammatory response syndrome (SIRS): a prospective study. JAMA. 1995:273(2):117-23.

24. Bagshaw SM, Lapinsky S, Dial S, Arabi Y, Dodek P, Wood G, et al. Acute kidney injury in septic shock: clinical outcomes and impact of duration of hypotension prior to initiation of antimicrobial therapy. Intensive Care Med. 2009;35(5):871-81.

25. Martin CM, Priestap F, Fisher H, Fowler RA, Heyland DK, Keenan SP, et al. A prospective, observational registry of patients with severe sepsis: the Canadian Sepsis Treatment and Response Registry. STAR registry investigators. Crit Care Med. 2009;37(1):81-8.

26. Palevsky PM, Zhang JH, O'Connor TZ, Chertow GM, Crowley ST, Choudhury $D$, et al. Intensity of renal support in critically ill patients with acute kidney injury. N Engl J Med. 2008;359(1):7-20.

27. Bellomo R, Farmer M, Wright C, Parkin G, Boyce N. Treatment of sepsisassociated severe acute renal failure with continuous hemodiafiltration: clinical experience and comparison with conventional dialysis. Blood Purif. 1995; 13(5):246-54

28. John S, Griesbach D, Baumgartel M, Weihprecht H, Schmieder RE, Geiger H. Effects of continuous haemofiltration vs intermittent haemodialysis on systemic haemodynamics and splanchnic regional perfusion in septic shock patients: a prospective, randomized clinical trial. Nephrol Dial Transpl. 2001; 16(2):320-7.

29. Hanafusa N. Application of continuous renal replacement therapy: what should we consider based on existing evidence? Blood Purif. 2015;40(4):312-9.

30. Wald R, McArthur E, Adhikari NKJ, Bagshaw SM, Burns KEA, Garg AX, et al. Changing incidence and outcomes following dialysis-requiring acute kidney injury among critically ill adults: a population-based cohort study. Am J Kidney Dis. 2015;65(6):870-7.

31. Bagshaw SM, Berthiaume LR, Delaney A, Bellomo R. Continuous versus intermittent renal replacement therapy for critically ill patients with acute kidney injury: a meta-analysis. Crit Care Med. 2008;36(2):610-7.

32. Zhang L, Yang J, Eastwood GM, Zhu G, Tanaka A, Bellomo R. Extended daily dialysis versus continuous renal replacement therapy for acute kidney injury: a meta-analysis. Am J Kidney Dis. 2015;66(2):322-30.

33. Prowle JR, Bellomo R. Continuous renal replacement therapy: recent advances and future research. Nat Rev Nephrol. 2010;6(9):521-9.
34. Schneider AG, Bellomo R, Bagshaw SM, Glassford NJ, Lo S, Jun M, et al. Choice of renal replacement therapy modality and dialysis dependence after acute kidney injury: A systematic review and meta-analysis. Intensive Care Med. 2013:39(6):987-97.

35. Schetz M, Gunst J, Van den Berghe G. The impact of using estimated GFR versus creatinine clearance on the evaluation of recovery from acute kidney injury in the ICU. Intensive Care Med. 2014;40(11):1709-17.

36. Bagshaw SM, Uchino S, Bellomo R, Morimatsu H, Morgera S, Schetz M, et al. Septic acute kidney injury in critically ill patients: clinical characteristics and outcomes. Clin J Am Soc Nephrol. 2007;2(3):431-9.

\section{Submit your next manuscript to BioMed Central and we will help you at every step:}

- We accept pre-submission inquiries

- Our selector tool helps you to find the most relevant journal

- We provide round the clock customer support

- Convenient online submission

- Thorough peer review

- Inclusion in PubMed and all major indexing services

- Maximum visibility for your research

Submit your manuscript at www.biomedcentral.com/submit
C) Biomed Central 